\title{
Cafeine improves memory performance during distraction in middle-aged, but not in young or old subjects
}

Citation for published version (APA):

Hogervorst, E., Riedel, W. J., Schmitt, J. A. J., \& Jolles, J. (1998). Cafeine improves memory performance during distraction in middle-aged, but not in young or old subjects. Human psychopharmacology, 13(4), 277-284. https://doi.org/10.1002/(SICI)1099-1077(199806)13:4<277::AID-HUP996>3.0.CO;2-W

Document status and date:

Published: 01/01/1998

DOI:

10.1002/(SICI)1099-1077(199806)13:4<277::AID-HUP996>3.0.CO;2-W

Document Version:

Publisher's PDF, also known as Version of record

Document license:

Taverne

Please check the document version of this publication:

- A submitted manuscript is the version of the article upon submission and before peer-review. There can be important differences between the submitted version and the official published version of record.

People interested in the research are advised to contact the author for the final version of the publication, or visit the DOI to the publisher's website.

- The final author version and the galley proof are versions of the publication after peer review.

- The final published version features the final layout of the paper including the volume, issue and page numbers.

Link to publication

\footnotetext{
General rights rights.

- You may freely distribute the URL identifying the publication in the public portal. please follow below link for the End User Agreement:

www.umlib.nl/taverne-license

Take down policy

If you believe that this document breaches copyright please contact us at:

repository@maastrichtuniversity.nl

providing details and we will investigate your claim.
}

Copyright and moral rights for the publications made accessible in the public portal are retained by the authors and/or other copyright owners and it is a condition of accessing publications that users recognise and abide by the legal requirements associated with these

- Users may download and print one copy of any publication from the public portal for the purpose of private study or research.

- You may not further distribute the material or use it for any profit-making activity or commercial gain

If the publication is distributed under the terms of Article 25fa of the Dutch Copyright Act, indicated by the "Taverne" license above, 


\title{
Caffeine Improves Memory Performance During Distraction in Middle-Aged, But Not in Young or Old Subjects
}

\author{
E. HOGERVORST*, W. J. RIEDEL, J. A. J. SCHMITT and J. JOLLES \\ Department of Psychiatry and Neuropsychology, Maastricht University, P.O. Box 616, 6200 MD Maastricht, \\ The Netherlands
}

\begin{abstract}
The present study evaluated the effect of caffeine $(225 \mathrm{mg}$ ) on cognitive performance in young, middle-aged, and old subjects in a placebo-controlled parallel groups design $(n=60)$. Groups were matched for level of education and sex. Positive effects of caffeine, as compared to placebo, were found in middle-aged subjects in the first trial of the word learning test. In contrast, caffeine had negative effects on the speed of searching short-term memory in young subjects. Caffeine had no effect on the intercept, which is an indicator for sensorimotor speed, of a memory scanning task. The middle-aged subjects appeared to regularly consume twice as much caffeine as the young and old subjects. These results were similar to earlier findings in a large population study. Although statistical analyses with habitual caffeine consumption as a covariate did not yield different results, a caffeine withdrawal effect was hypothesized to be responsible for the reduced cognitive performance of middle-aged subjects receiving placebo. The habitual use of large amounts of caffeine by middle-aged subjects may be a means to overcome the age-related decrease in cognitive functioning that is caused by changes in information processing. (C) 1998 John Wiley \& Sons, Ltd.
\end{abstract}

Hum. Psychopharmacol. Clin. Exp. 13: 277-284, 1998.

KEY WORDS - caffeine; age; cognition

\section{INTRODUCTION}

Caffeine is thought to act as a central stimulant and to have effects on cognitive functioning by enhancing alertness and vigilance (Goldstein and Kaizer, 1969; Lieberman et al., 1987). Although it has been reported that caffeine has no direct effects on memory functions (Loke, 1988), it was recently found that $250 \mathrm{mg}$ of caffeine could attenuate scopolamine-induced memory dysfunction without increasing psychomotor speed (Riedel et al., 1995b). This is of interest for studies of cognitive aging, in view of the decrease in memory functioning with age and the development of cognition enhancers.

The present study evaluated the effects of caffeine on memory and memory-related processes in a cross-sectional study involving three age groups (young, middle-aged, and old). Effects of caffeine in middle-aged subjects are especially interesting because of known differences in habitual caffeine

*Correspondence to: E. Hogervorst, Department of Psychiatry and Neurophychology, Maastricht University, P.O. Box 616, 6200 MD Maastricht, The Netherlands use between cohorts (Riedel et al., 1995a) and because cognitive performance has been found to be diminished in the fourth and fifth decades of life (Houx et al., 1991); Jolles et al., 1995a). Moreover, most studies generally compare young and old subjects. There have been relatively few studies of the effect of caffeine in ageing subjects. In a large population study of 7414 subjects, improved performance was associated with higher levels of caffeine consumption. Elderly subjects appeared more susceptible to the performance improving effects of caffeine on memory, visuospatial reasoning, and reaction time tasks (Jarvis, 1993). Yu et al. (1991) found that the performance of elderly subjects on a continuous attention test improved with caffeine relative to placebo. The elderly subjects also felt more alert, energetic, and interested with caffeine. Another study (Swift and Tiplady, 1988) reported that young and old subjects responded differently to caffeine. The authors suggested that the beneficial effects of caffeine in elderly subjects were possibly due to central mechanisms, as reflected by a decrease in the number of errors on cognitive tasks. The 
beneficial effects were not mediated by an increase in psychomotor speed, as they were in the younger subjects. Lorist et al. (1995), however, did not find substantial differences between the effects of caffeine on cognitive functions in elderly and young subjects. They found that caffeine could only partly counteract the decreased energetical resources of elderly subjects during task performance, in that caffeine counteracted the age-related performance decrement related to perceptual processes. However, caffeine had a similar beneficial effect in young, well rested subjects on stimulus evaluation. Caffeine did not affect central processes, ie the speed of searching short term memory.

It is thus currently unclear whether caffeine has a different effect in young or old subjects and at which levels of information processing caffeine acts. In the present study, the effect of $225 \mathrm{mg}$ of caffeine on sensorimotor and memory functions was investigated in young, middle-aged, and old subjects. Extreme care was taken to include only healthy subjects in view of the studies of Houx and Jolles that health-related factors influence neurocognitive performance in otherwise healthy subjects (Houx et al., 1991; Houx and Jolles, 1993; Jolles et al., 1995b). Because we were mainly interested in the performance of middle-aged subjects, we used a newly developed word learning test with distraction in which subjects had to ignore distracting auditory information. This test was used because it is potentially more sensitive for detecting subtle effects in middle-aged subjects as compared to the young subjects. We expected caffeine to have different effects in the three age groups.

\section{METHOD}

\section{Subjects}

Sixty healthy subjects were recruited by means of an advertisement in a local newspaper. The mean age of the young group $(n=20)$ was 29.4 (range: 26-34 years), the mean age of the middle aged group ( $n=20$ was $49 \cdot 6$ (range $46-54$ years), and the mean age of the eldest subjects $(n=20$ was 69.1 (range: 66-74 years). Subjects were preselected over the telephone. Only subjects without any previous adverse health-related factors were included (Houx et al.,1991; Houx and Jolles, 1993). Factors screened for were treatment by a neurologist/neurological disorders (e.g. cerebrovascular attacks, epilepsy, Parkinson's Disease, Multiple Sclerosis, or any other muscle or nerve

(C) 1998 John Wiley \& Sons, Ltd. disease, severe head trauma, encephalitis, or meningitis); cardiovascular disease (e.g. hypertension, arrythmia); internal disease (e.g. cancer, diabetes, thyroid disease, and renal dialysis); treatment by a psychiatrist and/or the presence of severe psychiatric disturbances (e.g. depression and electroshock treatment); the use of medication liable to induce cognitive deficits; and the excessive use of alcohol (>40 consumptions/week) or the use of addictive drugs. Lastly, subjects who had sensory and/or motor impairments which could be expected to affect psychomotor performance were excluded. Groups were matched for sex and level of occupational ability (LOA). Each group contained 10 males and 10 females. The LOA may be a better estimator of intelligence than education, especially in older subjects. For this purpose, occupation was given a four-digit code, based on a detailed functional description (CBS, 1985) that was transformed to a 7-point score, which ranged from 1 (simple labour requiring no education or a low level of skills) to 7 (highly specialized labour at an academic level) (van den Brandt et al., 1985). The LOA was derived from the Directorate General for Employment Policies in the Netherlands (1989). Each group contained subjects with 10 low and 10 high LOAs, the average LOA was $4 \cdot 5$. Subjects were asked how much coffee or tea they consumed a day. Caffeine consumption for each age group was shown in Figure 1.

\section{Procedure}

The study was a double-blind, placebo-controlled design, matched for sex and LOA. Groups were

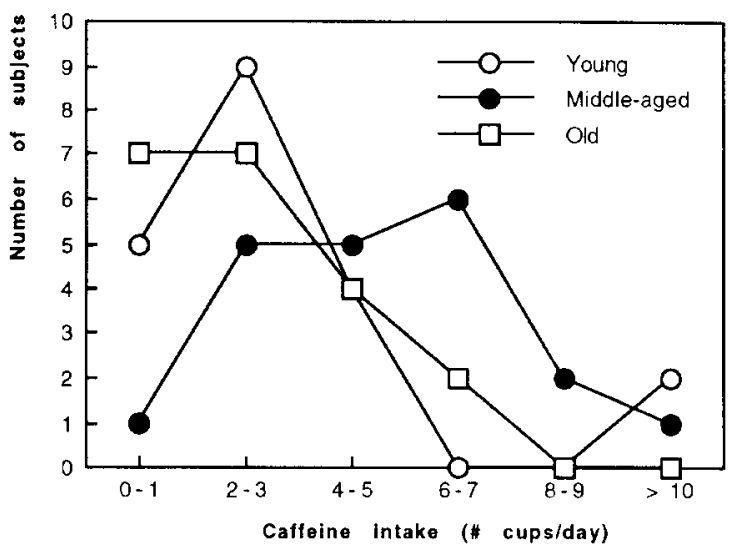

Figure 1. Caffeine intake in cups/day in young, middle-aged, and old subjects

HUMAN PSYCHOPHARMACOLOGY, VOL. 13, 277-284 (1998) 
order balanced for time of testing to avoid the influence of circadian factors. All testing was done in the morning. The entire procedure took $1.5 \mathrm{~h}$. Subjects were asked not to drink any alcoholic beverages in the $24 \mathrm{~h}$ prior to testing procedures and to arrive at the laboratory well rested. Subjects were asked not to drink any beverages containing caffeine or related substances, such as theophylline (coffee, chocolate, tea, or coca cola) on the morning of testing. On arrival in the laboratory, a saliva sample was collected and subjects were instructed to drink $225 \mathrm{mg}$ of caffeine in a total of three cups of coffee in $15 \mathrm{~min}$. For the placebo condition, $225 \mathrm{mg}$ of decaffeinated coffee was used. After half an hour there was a 15 -min training session. Thereafter, subjects started the test procedure, which took approximately $30 \mathrm{~min}$. Subjects were seated in front on an IBM compatible computer in a sound proof room. Standardized instructions were given through an intercom. After the experiment, subjects rinsed their mouth with water and a saliva sample was collected.

\section{Saliva caffeine analysis}

Saliva samples were taken before and after (about 75 min after caffeine consumption) experimental sessions. Samples were stored at $-22^{\circ} \mathrm{C}$. Saliva caffeine concentration was analysed using a highperformance liquid chromatography method.

\section{Psychological testing}

Two cognitive tests that are sensitive to the effects of aging were used.

Visual Verbal Learning Test with Auditory Distraction (VVLT-D). One of 12 parallel lists of 15 monosyllabic meaningful nouns, matched across word frequency, was presented on a computer screen connected to an IBM compatible computer at a rate of $2 \mathrm{~s}$ per word (Brand and Jolles, 1985). Simultaneously, 15 similar but different nouns were presented auditorily. Subjects were asked to verbally recall as many of the visually presented words as possible after the presentation had stopped, ignoring the (distracting) auditory words. The first trial was followed by four more trials in which the same words were repeated in the same order. The number of correctly recalled words were noted after each trial. The first trial was taken as an index of shortterm memory. The trial with the maximum number of recalled words is also taken as a dependent variable (immediate recall). Twenty minutes after completion of the fifth trial, subjects were asked to recall as many of the previously learned words as possible that were presented visually (delayed recall or long term memory).

Memory scanning. Subjects were briefly shown a set of unrelated consonants and told to memorize them. This is called the 'memory set' (Sternberg, 1969; Brand and Jolles, 1988). Subjects then looked at a series of 48 letters displayed for $1000 \mathrm{~ms}$ on a computer screen, connected to an IBM compatible computer; after $2000 \mathrm{~ms}$ the next letter appeared. Half of the presented letters were part of the memory set and had to be recognized as targets. The subjects' task was to respond as rapidly as possible by pressing either 'yes' or 'no' to indicate whether or not each successive letter was one of those from the memory set. The median of the response time (RT) for correct responses (on targets and non targets) was taken as a dependent parameter. This task was performed with memory sets consisting of 1,2 , and 3 letters, respectively. Individual $\mathrm{RT} \times$ set size functions were calculated. This function is defined by the equation $\mathrm{RT}=$ $\mathrm{A} * \mathrm{Ss}+\mathrm{B}$, in which $\mathrm{A}=$ slope of the function (i.e. the amount of extra time needed per item in the memory set), Ss = size of the memory set, and $\mathrm{B}=$ intercept with the Y-axis. The slope is a measure of the speed of scanning short term memory, and the intercept is a measure of sensorimotor speed.

\section{STATISTICS}

The results were analysed using a two-way analysis of variance (ANOVA) with the factor 'drug' (caffeine, placebo) and the factor 'age' (young, middle-aged, old). For habitual caffeine use, nonparametric analyses (respectively Kruskal-Wallis and Mann-Whitney runs test) were carried out. All analyses were done with the SPSS-PC statistics package for Apple Macintosh. The cognitive test performance of the various groups is given in Table 1.

\section{RESULTS}

\section{Saliva caffeine concentrations}

Three (1 caffeine, 2 placebo) subjects in the middleaged group had pretreatment saliva caffeine concentrations slightly over $2.0 \mathrm{mg} / 1$, which suggested 
Table 1. Outcome (mean and SD) of test performance measures in young $(n=20)$, middle-aged $(n=17)$, and elderly subjects $(n=20)$ with caffeine $(n=10)$ or placebo $(n=10)$

\begin{tabular}{|c|c|c|c|c|c|c|c|}
\hline \multirow[t]{2}{*}{ Test-subtest } & \multirow[t]{2}{*}{ Measure } & \multicolumn{2}{|c|}{ Young } & \multicolumn{2}{|c|}{ Middle-aged } & \multicolumn{2}{|c|}{ Old } \\
\hline & & Caffeine & Placebo & Caffeine & Placebo & Caffeine & Placebo \\
\hline VVLT-Trial 1 & (No. of words) & $5.0(1.7)$ & $6 \cdot 0(1.5)$ & $5 \cdot 3(1 \cdot 1)^{*}$ & $4.0(1 \cdot 1) \dagger$ & $4.3(1.8)$ & $4 \cdot 1(1 \cdot 2)$ \\
\hline Max immediate recall & (No. of words) & $12 \cdot 6(1 \cdot 3)$ & $12 \cdot 9(1 \cdot 1)$ & $12 \cdot 2(1 \cdot 7)^{*}$ & $11.5(1.2) \dagger$ & $11.4(1.7)$ & $11 \cdot 3(1 \cdot 7)$ \\
\hline Delayed recall & (No. of words) & $10 \cdot 6(1.5)$ & $11 \cdot 3(1 \cdot 8)$ & $9.8(1.8)^{*}$ & $9 \cdot 0(3.0) \dagger$ & $8.7(2.8)$ & $9.8(2.4)$ \\
\hline \multirow[t]{2}{*}{ Memory Scanning } & Intercept (ms) & $425(47)$ & $433(38)^{*}$ & $466(40) \dagger$ & $455(46) \dagger$ & $510(72)$ & $502(71)$ \\
\hline & Slope (ms) & $56(15)^{*}$ & $38(17) \dagger$ & $41(15) \dagger$ & $53(17) \dagger$ & $47(15)$ & $57(18)$ \\
\hline
\end{tabular}

$* n=9 . \dagger n=8$.

that they had not adhered to the abstinence instructions. Data for these subjects, who had an average habitual caffeine use, were not used in the analyses. The overall average pretreatment saliva caffeine concentration in the remaining subjects was $0.34 \mathrm{mg} / 1 \quad(\mathrm{SD}=0.44)$, which was not different between conditions [CAF: $\mathrm{M}=0.37(\mathrm{SD}=0.45)$, PLAC: $\quad \mathrm{M}=0.31 \quad(\mathrm{SD}=0.43), \quad F(1,54)=0.32$, $p=\mathrm{ns}]$. Saliva caffeine concentrations were higher in the subjects that had received caffeine-containing coffee $(\mathrm{M}=3.12 \mathrm{mg} / 1, \mathrm{SD}=1.47)$ than the subjects who had received decaffeinated coffee $(\mathrm{M}=$ $0.33 \mathrm{mg} / 1, \mathrm{SD}=0.46)[F(1,54)=93.2, p<0.0001]$.

\section{Performance}

A 2 (drug) $\times 3$ (age) analysis of variance of performance on the VVLT-D revealed a main effect of age on the number of words recalled during the first trial $(F(2,51)=4 \cdot 10, p<0 \cdot 05]$. There was no significant main effect of caffeine on trial 1 $[F(1,51)=0 \cdot 09, p=\mathrm{ns}]$. There was a trend significant interaction effect of age and caffeine on trial 1 $[F(2,51)=2.99, p=0 \cdot 06]$. Figure 2 shows that the middle-aged subjects receiving placebo stored less words in short-term memory than did the subjects receiving caffeine.

There was a significant main effect of age on the maximum number of words recalled over the five trials $[F(2,51)=4.57, p<0.05]$ (Table 1). Caffeine had no main effect on the maximum number of words recalled $[F(1,51)=0 \cdot 14, p=$ n.s.]. Also, no interaction effects were seen between age and caffeine on the maximum number of words recalled $[F(2,51)=0.55, p=$ n.s.]. There was a significant main effect of age on the delayed recall $[F(2,51)=$ $3.32, p<0.05$ ] (Table 1). Caffeine did not have a main effect on delayed recall $[F(1,51)=0 \cdot 44$, $p=$ n.s.] and also no interaction effect between age

(C) 1998 John Wiley \& Sons, Ltd.

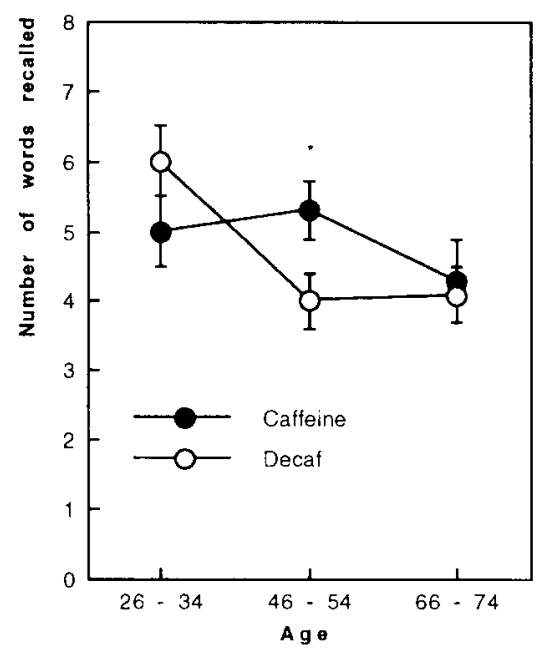

Figure 2. Number of words recalled on trial 1 (of the VVLT) with cafeine or placebo (decaf) over age groups. ${ }^{*}[t(15)=2 \cdot 51$, $p<0 \cdot 05]$

and caffeine could be detected $[F(2,51)=0 \cdot 85$, $p=\mathrm{n} . \mathrm{s}$.$] .$

No main effect of age $\left[F(2,47)^{*}=0 \cdot 53, p=\right.$ n.s. $]$ was seen on the slope of the Memory Scanning Task. Hence, age did not affect the speed of searching short-term memory. In addition, no main effect of caffeine was detected $[F(1,47)=0 \cdot 12, p=$ n.s.]. However, there was a significant interaction effect between age and caffeine on the slope of the Memory Scanning Task $[F(2,47)=4 \cdot 58, p<0.05]$. Figure 3 shows that in the young group, the slope was significantly lower for the subjects who received

*Four subjects (3 young, 1 middle-aged) were not included in the analyses of the slope, since these data were missing due to computer failure. Two subjects (one young, one middle-aged) were missing in the intercept data. 


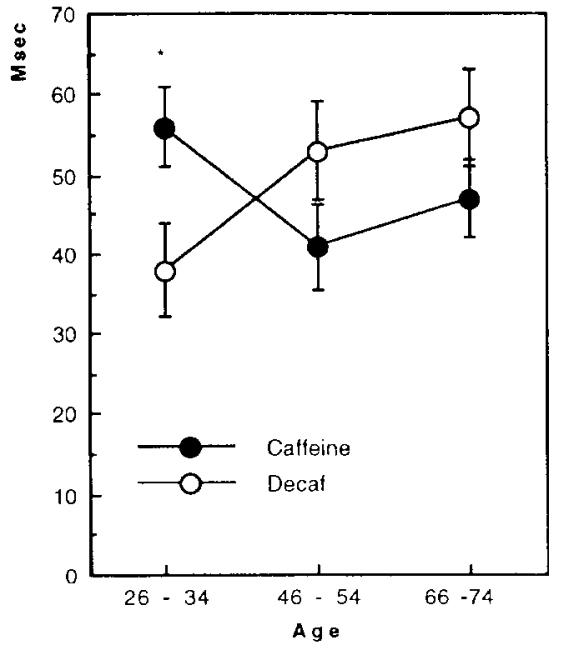

Figure 3. Speed of search in short-term memory of a memory scanning task with caffeine or placebo (decaf) over age groups. $*[t(15)=2 \cdot 35, p<0 \cdot 05]$

placebo than for the subjects who received caffeine. Age clearly affected sensorimotor speed, as a 3 (age) $\times 2$ (caf/placebo) ANOVA on the 1-intercept showed $[F(2,49)=9 \cdot 67, p=0 \cdot 001]$. However, caffeine did not affect sensorimotor speed $[F(1,49)=0 \cdot 05, p=$ n.s. $]$ and no interaction effect of age and caffeine was detected $[F(2,49)=0 \cdot 15$, $p=\mathrm{n} . \mathrm{s}$.$] .$

\section{Habitual use}

The three age groups differed in the average amount of caffeine consumed per day $\left[\chi^{2}(57)=\right.$ $10 \cdot 89, p<0 \cdot 005]$. Young subjects consumed $3 \cdot 2$ (median: $2 \cdot 8, \mathrm{SD}=2 \cdot 6$ ) cups of coffee/day, middleaged subjects consumed 5.4 (median: $5 \cdot 3, \mathrm{SD}=$ $2 \cdot 8$ ) cups of coffee/day, and old subjects consumed $2 \cdot 6$ (median: $2 \cdot 1, \mathrm{SD}=2 \cdot 0$ ) cups of coffee/ day. The mean amount of caffeine was similar for the young and old subjects (2-3 cups of coffee/day, $Z=-0.69, p=$ n.s.) and significantly lower than that of the middle-aged subjects (versus young: $Z=-2.60, \quad p<0.01$; old: $Z=3 \cdot 06, p<0 \cdot 005)$.

\section{DISCUSSION}

The objective of the present study was to evaluate the effects of caffeine on cognitive functions in three age groups: young, middle-aged, and old healthy subjects. The results show that caffeine had selective effects on cognitive performance in the three age groups. First, as expected, age affected performance in the verbal learning test with distraction and also clearly affected sensorimotor speed, as measured from the intercept of the memory scanning task. Age did not affect the speed of searching short-term memory, as measured from the slope of the memory scanning task. Furthermore, young subjects who drank caffeine containing coffee needed significantly more time to search short-term memory than did young subjects who drank decaffeinated coffee (placebo). By contrast, in the middle-aged subjects, caffeine had a positive effect on short-term memory functions, as measured with the first trial of the word list task. More words were retained in memory after consumption of caffeine than after consumption of decaffeinated coffee. Caffeine did not affect maximum and delayed recall of the word list task, or the sensorimotor speed parameters of a memory scanning task.

There are various factors which may explain the different effects of caffeine on short-term memory functions in the three age groups. In the first place, since the pharmacokinetics of caffeine do not change with age (Blanchard and Sawers, 1983), the difference in the response to caffeine in the different age groups is thought to have a pharmacodynamic basis. However, there was a difference in habitual use of caffeine in the three age groups. The middle-aged subjects drank almost twice as much coffee a day as the young and old subjects. The groups were not a priori matched for habitual caffeine consumption in order to conform to standard procedures in cross-sectional studies in cognitive aging research, where caffeine use is not a matching criterion. Similar cohort differences in the regular use of caffeine have been reported earlier (Riedel et al., 1995a), where young subjects were seen to drink on average 3 cups of coffee/day, middle aged 5 cups, and old subjects 3.5 cups. Cohort differences in the use of nicotine have also been found (Hogervorst et al., 1995). These differences are usually controlled by statistical procedures. We also performed statistical analyses with the number of cups of coffee consumed per day as a covariate. The results remained essentially the same and $F$-values remained in the same order. This can be taken to indicate that inter-subject differences in habitual caffeine consumption were not the major determinant of differences in the effects of caffeine found in the present study. Yet, habitual caffeine use has been shown to affect 
the outcome of tasks which measure memory or memory-related processes. Loke (1988), for example, found that regular caffeine users (388$928 \mathrm{mg} /$ week) recalled more words after a delay than very low caffeine $(<178 \mathrm{mg})$ users. Likewise, Smith et al. (1991) reported that moderate to high habitual users of caffeine (>200 mg/day) had increased sensitivity on a vigilance task. This may explain the absence of effects in our low caffeineconsuming elderly subjects.

Further, a high habitual use may also render subjects more sensitive to caffeine withdrawal effects. This could be a second explanation for the findings of the present study. However, the effect of caffeine withdrawal on cognitive functions is disputed (James, 1994). The performance of habitual caffeine consumers on simple tasks is reported to decrease during caffeine deprivation (Silverman et al., 1992). Furthermore, in coffeedrinking managers (Streufert et al., 1995) cognitive effectiveness during complex task performance was diminished during caffeine deprivation. Lieberman et al. (1987) showed than even very low does of caffeine (32 mg) enhanced cognitive function (vigilance and RT) after caffeine abstinence for $12 \mathrm{~h}$. There is some dispute whether caffeine deprivation in habitual caffeine consumers is the only explanation for the enhancing effect of caffeine on cognitive functions (Rogers et al., 1995; Warburton, 1995). In the study performed by Warburton (1995), the effect of low doses of caffeine (75 and $150 \mathrm{mg}$ ) was investigated after a minimal caffeine abstinence of $1 \mathrm{~h}$. Attention, problem solving, and delayed recall were improved, but immediate recall and short-term memory were not. However, performance in the placebo condition was close to the maximum, giving little margin for improvement. Hence, even without caffeine deprivation, subjects in the caffeine condition still improved their cognitive performance. Yet, in view of the fact that our middle-aged subjects used nearly twice as much caffeine as the young and the old subjects, the effect of caffeine withdrawal was probably much more pronounced in the middle-aged subjects than in the other subjects. This is interesting because it may provide clues as to the mechanisms of action of changes in cognition in relation to age. Young subjects, for example, have an optimal cognitive performance and it is possible that middle-aged subjects use coffee to compensate for the deterioration of cognitive functions with age. Also, many studies have shown that a decline in cognitive performance is already evident in the fourth decade
(Jolles et al., 1995b; Houx et al., 1991; Houx and Jolles, 1993). This hypothesis is currently being tested in the Maastricht Aging Study, which is a large scale longitudinal study involving 1980 subjects aged 25-80 (Jolles et al., 1995a).

The effect of caffeine taken together with the deterioration of information processing resources with age may explain the differences in caffeine/ age effects in the present study. Salthouse (1988) suggested that the age-related decrease in shortterm memory capacity reflects the decrease in resources available with advancing age. According to the model of Hasher and Zacks (1979), sensitivity to difficult tasks which require effortful information processing increases with age because these tasks require attention and energetic capacity, or resources. Moreover, elderly subjects are more sensitive to distracting information and find it difficult to actively suppress irrelevant information (Carlson et al., 1995; Kane et al., 1994). Caffeine positively affects the ability to focus attention (Lorist et al., 1994, 1995). The model of Hasher and Zacks (1979) combined with the positive effect that caffeine has no selective attention may explain why caffeine had an effect on performance in the first trial of the word list in middle-aged subjects, but not in young subjects. Caffeine increased the number of words recalled by reducing the susceptibility to the distracting, auditorily presented words, but only in the middle-aged subjects because these subjects are more sensitive to distraction and will profit from the effect of caffeine on selective or focused attention. The more structural deficits (loss of neural connections) of elderly subjects may explain the absence of positive effects of caffeine in this age-group. A third explanation of our findings thus involves the known effects of caffeine on attentional functions (Lorist et al., 1994; Nehlig et al., 1992). Similarly to our finding, others have reported negative effects of caffeine on the slope of a memory scanning task performed by young subjects (Anderson et al., 1989). However, caffeine has also been reported to have significant positive effects on sensorimotor speed (intercept) (Anderson et al., 1989; Lorist et al., 1994, 1995). The absence of intercept effects in the present study may be because our task was of short duration and caffeine is known to increase the ability to sustain attention or to maintain vigilance (Nehlig et al., 1992; Pons et al., 1987; Yu et al., 1991). Furthermore, as for the effects of caffeine on other aspects of information processing, in the present study caffeine did not affect maximum and 
delayed recall. Hence, these data suggest that caffeine does not affect storage and consolidation functions.

In sum, age-related changes in information processing may thus underlie the effects of caffeine on cognitive performance. It remains to be established whether there is a dose-dependent relationship in this respect. There is convincing evidence that in young subjects caffeine does not affect performance in a linear dose-dependent manner. Rather, the dose-response relationship follows an inverted U-shaped curve analogous to the relation of performance and arousal which is described by the Yerkes-Dodson law (1908). For instance, Loke (1988) reported in her literature review that memory span increases with low (e.g. $162 \mathrm{mg}$ ) but not with high $(325 \mathrm{mg})$ doses of caffeine. In the present study, $225 \mathrm{mg}$ of caffeine had a negative effect on the short-term memory performance of young subjects, but did not affect delayed recall. Anderson et al. (1989), who showed a negative effect of caffeine on short-term memory functions, used a comparable dose of $4 \mathrm{mg} / \mathrm{kg}$ caffeine. Interestingly, delayed recall has been shown to increase with $200 \mathrm{mg}$, but to decrease with $400 \mathrm{mg}$ of caffeine, while $325 \mathrm{mg}$ had no effect (see also Smith et al., 1992; Terry and Phifer, 1986). It may be the case that, because arousal decreases with age, the Yerkes-Dodson curve moves to a position more to the right. This would explain why caffeine had negative effects in young subjects, positive effects in our middle-aged subjects and no effect in the elderly subjects.

Concluding, results show that age has subtle effects on memory functions under conditions of distraction. In addition, caffeine has different effects on cognitive performance in different age-groups. The decreased performance in the middle-aged subjects who drank decaffeinated coffee may be due to a caffeine withdrawal effect, which is stronger than in subjects of other ages because the habitual caffeine consumption in middle-aged subjects was twice as high. The present findings are important for cognitive aging research in view of the fact that cross-sectional studies usually do not control for caffeine use. In addition, the neurocognitive paradigm used (measurement of memory performance under distraction) may prove relevant to cognitive aging research. The habitual use of large amounts of caffeine by middle-aged subjects may be a means to overcome the age-related decrease in cognitive functioning that is caused by changes in information processing.

\section{ACKNOWLEDGEMENT}

The caffeine saliva sample analyses were made possible by a grant from the Institute for Scientific Information on Coffee, Paris.

\section{REFERENCES}

Anderson, K. J., Revelle, W. and Lynch, M. J. (1989). Caffeine, impulsivity, and memory scanning: a comparison of two explanations for the Yerkes-Dodson effect. Motivation and Emotion, 8, 614-624.

Blanchard, J. and Sawers, S. J. (1983). Comparative pharmacokinetics of caffeine in young and elderly men. Journal of Pharmacokinetics and Biopharmacology, 11(2), 109-126.

Brand, N. and Jolles, J. (1985). Learning and retrieval rate of words presented auditorily and visually. Journal of General Psychology, 112, 201-210.

Brand, N. and Jolles, J. (1988). Neuropsych: computerassisted neuropsychological assessment. In Computers in Psychology: Methods, Instrumentation, \& Psychodiagnostics, Maarsse, P. J., Mulder, L. J. H., Sjouw, W. P. B. and Akkermans, A. E. (Eds), Swets \& Zeitlinger, Amsterdam, pp. 149-157.

Brandt, P. A., van den Goldbohm, R. A., van't Veer, P., Volovics, A., Hermus, R. J. J. and Sturmans, F. (1985). A large-scale prospective cohort study on diet and cancer in the Netherlands. Journal of Clinical Epidemiology, 43, 285-295.

Carlson, M. C., Hasher, L., Zacks, R. T. and Connelly, S. L. (1995). Aging, distraction, and the benefits of predictable location. Psychology and Aging, 10, 427-436.

Centraal Bureau voor Statistiek, CBS (1985). Beroepenclassificatie 1984, 2nd edn. Voorburg.

Directorate General for Employment Policies (1989). Handleiding voor de functie-analyse (Manual for job analysis). SDU Uitgeverij, Den Haag.

Golstein, A. and Kaizer, S. (1969). Psychotropic effects of caffeine in man, III. A questionnaire survey of coffee drinking and its effects on a group of housewives. Clinical Pharmacology Therapy, 10, 477-488.

Hasher, L. and Zacks, R. T. (1979). Automatic and effortful processes in memory. Journal of Experimental Psychology: General, 108, 356-388.

Hogervorst, E., Riedel, W. J., van Boxtel, M. P. J. and Jolles, J. (1995). Smoking and cognitive complaints. In The Maastricht Aging Study, Jolles, J., Ponds, R., van Boxtel, B. P. J. and Houx, P. (Eds), Neuropsych, Maastricht, pp. 105-111.

Houx, P. J. and Jolles, J. (1993). Age-related decline of psychomotor speed: effects of age, brain health, sex, and education. Perceptual and Motor Skills, 76, $195-211$.

Houx, P. J., Vreeling, F. W. and Jolles, J. (1991). Ageassociated cognitive decline is related to biological life

HUMAN PSYCHOPHARMACOLOGY, VOL 13, 277-284 (1998) 
events. In Alzheimer's Disease: Basic Mechanisms, Disgnosis, and Therapeutic Strategies, Iqbal, K., McLachlan, D. R. C., Winblad, B. and Wisniewski, H. M. (Eds), John Wiley, Chichester, pp. 353-359.

James, J. E. (1994). Does caffeine enhance or merely restore degraded psychomotor performance? Biological Psychology/Pharmacopsychology, 30, 124-125.

Jarvis, M. J. (1993). Does caffeine intake enhance absolute levels of cognitive performance. Psychopharmacology, 110, 45-52.

Jolles, J., Ponds, R., van Boxtel, M. P. J. and Houx, P. (1995a). The Maastricht Aging Study. Neuropsych, Maastricht.

Jolles, J., Verhey, F. R. J., Riedel, W. J. and Houx, P. J. (1995b). Cognitive impairment in elderly people: predisposing factors and implications for experimental drug studies. Drugs and Aging, 7, 459-479.

Kane, M. J., Hasher, L., Stoltzfus, E. R., Zacks, R. T. and Connelly, S. L. (1994). Inhibitory attentional mechanisms and aging. Psychology and Aging, 9, 103-112.

Lieberman, H. R., Wurtman, R. J., Emde, G. G., Roberts and Coviella, I. L. G. (1987). The effects of low doses of caffeine on human performance and mood. Psychopharmacology, 92, 308-312.

Loke, W. H. (1988). Effects of caffeine on mood and memory. Physiology and Behaviour, 44, 367-372.

Lorist, M. M., Snel, J., Kok, A. and Mulder, G. (1994). Influence of caffeine on selective attention in wellrested and fatigued subjects. Psychophysiology 31, $525-534$.

Lorist, M. M., Snel, J., Mulder, G. and Kok, A. (1995). Aging, Caffeine, and information processing: an event-related potential analysis. Electroencephalography and Clinical Neurophysiology, 96, 453-467.

Nehlig, A., Daval, J. L. and Debry, G. (1992). Caffeine and the central nervous system: mechanisms of action, biochemical, metabolic, and psychostimulant effects. Brain Research Reviews, 17, 139-170.

Pons, L., Trenque, T., Bielecki, M., Moulin, M. and Portier, J. C. (1987). Attentional effects of caffeine in man: comparisons with drugs acting upon performance. Psychiatry Research, 23, 329-333.

Riedel, W. J., Hogervorst, E. and Jolles, J. (1995a). Cognition enhancers and aging. In The Maastricht Aging Study, Jolles, J., Ponds, R., van Boxtel, M. P. J. and Houx, P. (Eds), Neuropsych, Maastricht, pp. 149-157.
Riedel, W. J., Hogervorst, E., Leboux, R. L. A. M., Verhey, F. R. J., Praag, H. M. van and Jolles, J. (1995b). Caffeine enhances memory after cholinergic blockade. Psychopharmacology, 122, 158-168.

Rogers, P. J., Richardson, N. J. and Dernoncourt, C. (1995). Caffeine use: is there a net benefit for psychomotor performance. Neuropsychobiology, 31, 195-199.

Salthouse, T. A. (1988). Resource reduction interpretations of cognitive aging. Brain and Cognition, 7, $238-272$.

Silverman, K., Evans, S. M., Strain, E. C. and Griffiths, R. R. (1992). Withdrawal syndrome after the double blind cessation of caffeine consumption. The New England Journal of Medicine, 327, 1109-1113.

Smith, A. P., Kendrick, A. and Maben, A. (1992). Use and effects of food and drinks in relation to daily rhythms of mood and cognitive performance. Proceedings of the Nutrition Society, 51, 325-333.

Smith, B. D., Rafferty, J., Lindgren, K., Smith, D. A. and Nespor, A. (1991). Effects of hibitual caffeine use and acute ingestion: testing a biobehavioral model. Physiology and Behavior, 51, 131-137.

Sternberg, S. (1969). Memory scanning: mental processes revealed by reaction time experiments. American Scientist, 57, 421-457.

Streufert, S., Pogash, R., Miller, J., Gingrich, D., Landis, R., Lonardi, L., Severs, W. and Roache, J. D. (1995). Effects of caffeine deprivation on complex human functioning. Psychopharmacology, 118, 377-384.

Swift, C. G. and Tiplady, B. (1988). The effect of age on the response of caffeine. Psychopharacology, 94, 29-31.

Terry, W. S. and Phifer, B. (1986). Caffeine and memory performance on the AVLT. Journal of Clinical Psychology, 42, 860-863.

Warburton, D. M. (1995). Effects of caffeine on cognition and mood without caffeine abstinence. Psychopharmacology, 119, 66-70.

Yerkes, R. M. and Dodson, J. D. (1908). The relation of strength to stimuli to rapidity of habituation. Journal of Comparative Neurology and Psychology, 18, 459-482.

Yu, G., Maskray, V., Jackson, S. H. D., Swift, C. G. and Tiplady, B. (1991). A comparison of the central nervous system effects of caffeine and theophylli in elderly subjects. British Journal of Clinical Pharmacology, 32, 341-345. 